\title{
BENEFICIAMENTO E CARACTERIZAÇÃO DE QUARTZO PARA OBTENÇÃO DE SILÍCIO GRAU METALÚRGICO
}

\author{
L. G. L. Soares ${ }^{1,2}$; E. B. da Silva ${ }^{1}$; F. M. S. Garrido ${ }^{1}$; F. A. N. G. da Silva ${ }^{1}$; R. S. Amado ${ }^{1}$, J. A. Sampaio ${ }^{2}$ \\ ${ }^{1}$ Universidade Federal do Rio de Janeiro / Instituto de Química - UFRJ \\ ${ }^{2}$ Centro de Tecnologia Mineral - CETEM \\ livia_leida@yahoo.com.br-jsampaio@cetem.gov.br
}

Artigo submetido em outubro/2012 e aceito em outubro/2012

\section{RESUMO}

Este trabalho descreve as etapas de caracterização e purificação de quartzo para obtenção de um silício grau metalúrgico (SiGM) com baixo nível de impurezas. A amostra de quartzo, após as etapas de britagem, calcinação seguida de quenching e moagem autógena apresentou um teor de $\mathrm{SiO}_{2}$ de $99,5 \%$, isto é, um aumento de aproximadamente $2 \%$ em relação a amostra original. A análise granulométrica indicou que a fração abaixo de $37 \mu \mathrm{m}$, correspondente a apenas 2,06\% da amostra total, apresenta alto teor de impurezas, podendo ser removida, facilitando assim os ensaios de purificação. O estudo demonstrou que a amostra de quartzo beneficiada apresenta um potencial uso à produção de SiGM.

PALAVRAS-CHAVE: Silício grau metalúrgico, Quartzo, Beneficiamento.

\section{ORE DRESSING AND CHARACTERIZATION OF QUARTZ IN ORDER TO OBTAIN THE METALLURGICAL GRADE SILICON}

\begin{abstract}
This work describes the characterization and purification stages for quartz in order to obtein the metallurgical grade silicon (SiGM) with low impurities content. The sample of quartz, after cruched, calcination followed by quenching and autogen griding, showed the $\mathrm{SiO}_{2}$ content of $99,5 \%$, an increase of approximately $2 \%$ on the original sample. The particle
\end{abstract}

size analysis indicated that the fraction under $37 \mu \mathrm{m}$, matching only $2,06 \%$ of the total sample, presents high impurities content, can be removed, thus facilitating the purification stages. The study showed that the quartz's sample ore dressed has a potential use for the production of SiGM.

KEY-WORDS: Metallurgical grade silicon, Quartz, Ore dressing. 


\section{BENEFICIAMENTO E CARACTERIZAÇÃO DE QUARTZO PARA OBTENÇÃO DE SILÍCIO GRAU METALÚRGICO}

\section{INTRODUÇÃO}

A indústria tem investido em fontes alternativas de energia, como a fotovoltaica, eólica, geotérmica, hidroelétrica, etc., de forma a reduzir a dependência de fontes não renováveis de energia, provenientes, principalmente, de combustíveis fósseis que geram gases que impactam o meio ambiente ${ }^{1}$.

O interesse pela produção de energia associada ao desenvolvimento sustentável torna-se mais intenso a cada ano. Neste sentido, o uso da energia solar, como fonte alternativa, avança de forma progressiva, estimulado pelas características favoráveis de ser uma energia limpa e abundante. $O$ sol fornece ao nosso planeta uma grande quantidade de energia $\left(3 \times 10^{24} \mathrm{~J} \mathrm{ano}^{-1}\right)$ e esta luz solar pode, em princípio, sustentar todas as necessidades de energia tanto atuais quanto futuras ${ }^{2}$.

A energia solar pode ser aproveitada através do uso das células fotovoltaicas, também chamadas de células solares, que permitem que a luz do sol (radiação eletromagnética) seja captada e transformada em energia elétrica (efeito fotovoltaico). A energia obtida desta forma apresenta vantagens como não ser poluente, ser renovável, ter manutenção simples e não necessitar de longas linhas de transmissão.

O Silício é um semicondutor com elevada abundância na crosta terrestre e é o material mais utilizado para a fabricação de células fotovoltaicas $(\sim 90 \%)^{3}$, nas quais se utiliza um Silício com elevado grau de pureza, conhecido como Silício Grau Solar (SiGS). A principal matériaprima básica para obtenção do silício SiGS é o quartzo, que por meio de uma reação carbotérmica se transforma no Silício Grau Metalúrgico (SiGM). O silício SiGM é produzido comercialmente a partir da redução do $\mathrm{SiO}_{2}$ (quartzo) em fornos do tipo arco submerso, para produção em larga escala ${ }^{4}$. Neste caso, esse produto deve possuir um teor de Silício entre 98,0 e $99,5 \%^{5}$.

Porém, este teor de Silício ainda é inapropriado à produção de células fotovoltaicas em decorrência do elevado índice de impurezas, com destaque para os teores dos elementos dopantes, ou seja, os elementos Boro e Fósforo.

Estes elementos dopantes são importantes para se formar uma junção pn, que se trata de uma lâmina de Sílicio, inicialmente puro, que é dopada em uma de suas metades com átomos de boro, e na outra, dopada com átomos de fósforo. Os átomos de silício possuem quatro elétrons em sua última camada de valência que se ligam aos seus átomos vizinhos formando uma rede cristalina. Ao adicionar átomos de fósforo, que possuem cinco elétrons, o sistema ficará com um elétron em excesso que não poderá ser emparelhado. Isto faz com que este elétron fique fracamente ligado ao seu átomo de origem, tendendo a ocupar a banda de condução. Ao adicionar átomos de boro, que possui apenas três elétrons, haverá falta de um elétron para satisfazer as ligações com os átomos de silício da rede. Esta falta de elétron é denominada buraco ou lacuna, sendo que esta fica localizada na banda de valência, que apresenta menor energia. Nessa condição, um elétron de um sítio vizinho poderá passar para esta lacuna, fazendo com que o buraco se desloque. 
Assim, o Fósforo é um dopante doador de elétrons e denomina-se dopante $\mathbf{n}$, enquanto que, o Boro é um dopante receptor de elétrons e é denominado dopante $\mathbf{p}$. Com a formação da junção pn, e esta sendo exposta a fótons com energia maior que o gap de condução, haverá a geração de pares elétron-lacuna provocando um deslocamento de cargas, fazendo surgir assim uma diferença de potencial ${ }^{6}$.

A existência dessas impurezas, no silício SiGM, torna indispensáveis as etapas de purificação para removê-las, já que esses elementos dopantes são adicionados ao silício purificado (SiGS), de forma controlada, durante as etapas finais de preparação do semicondutor. Isto é, são adicionados às lâminas de silício em concentrações definidas.

Desta forma, o objetivo geral de nosso trabalho foi o de beneficiar e caracterizar uma amostra de quartzo para obtenção de um óxido de silício $\left(\mathrm{SiO}_{2}\right)$ de elevado grau de pureza, com a finalidade de produzir, em uma etapa posterior, um silício SiGM de alta pureza. Neste trabalho será dado destaque para os resultados relacionados às impurezas associadas aos elementos boro e fósforo.

\section{MATERIAIS E MÉTODOS}

Inicialmente foi realizada a coleta da amostra no município de Tanhaçu, BA, onde há uma jazida de quartzo com elevado grau de pureza. Na etapa de preparação da amostra, efetuou-se o quarteamento da mesma em pilha de homogeneização, da qual foram coletadas alíquotas de 5,0 kg. Em seguida, foi feita a cominuição da amostra utilizando um britador de mandíbula, operando em circuito fechado, com uma peneira de abertura de 6,35 $\mathrm{mm}$.

O produto do britador foi homogeneizado em pilha de homogeneização da qual foram coletadas alíquotas de $200 \mathrm{~g}$ para o desenvolvimento dos trabalhos. Desse modo, foi realizada a análise granulométrica a úmido em um peneirador vibratório $(684,5 \mathrm{rpm})$ equipado com um conjunto de peneira de abertura desde $2,36 \mathrm{~mm}$ a $37 \mu \mathrm{m}$, segundo a série Tyler. Todas as frações da análise granulométrica foram secas em estufa $\left(100^{\circ} \mathrm{C}\right)$, pesadas e enviadas à caracterização por meio da difração de raios X (DRX).

Uma alíquota retirada da pilha de homogeneização foi moída em moinho autógeno, por $2 \mathrm{~h}$. O moinho autógeno consiste em utilizar como meio moedor o próprio material, com o objetivo de evitar a contaminação da amostra (Figura 1). O produto da moagem foi enviado à caracterização por DRX e por emissão ótica por plasma indutivamente acoplado (ICP-OES).

Por fim, uma outra alíquota obtida do ensaio de britagem foi submetida à calcinação a $900^{\circ} \mathrm{C}$ por 60, 90 e 120 minutos, seguidos de quenching (resfriamento brusco do material), com o objetivo de facilitar a moagem e remover possíveis impurezas. Os materiais obtidos foram encaminhados para análise por ICP-OES, para ser avaliado em qual tempo de calcinação pode-se obter um quartzo com menor quantidade de impurezas. 


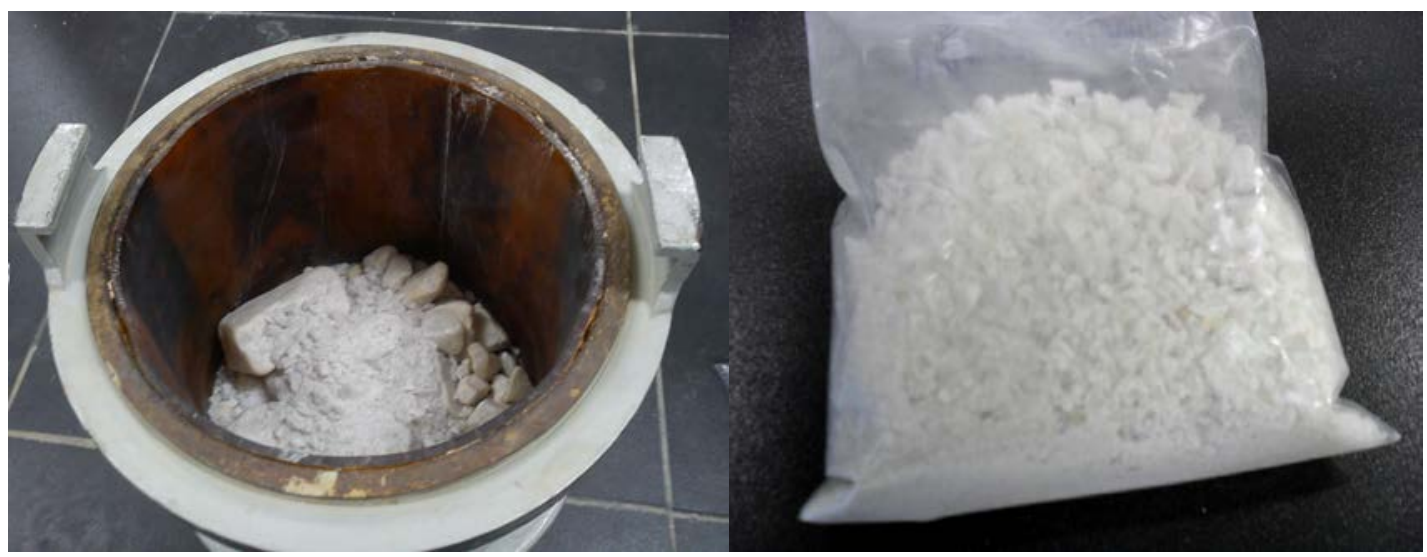

(a)

(b)

Figura 1 - Moinho autógeno (a) e a amostra após o processo de moagem (b).

Em resumo, os procedimentos são descritos pelo fluxograma apresentado na Figura 2.

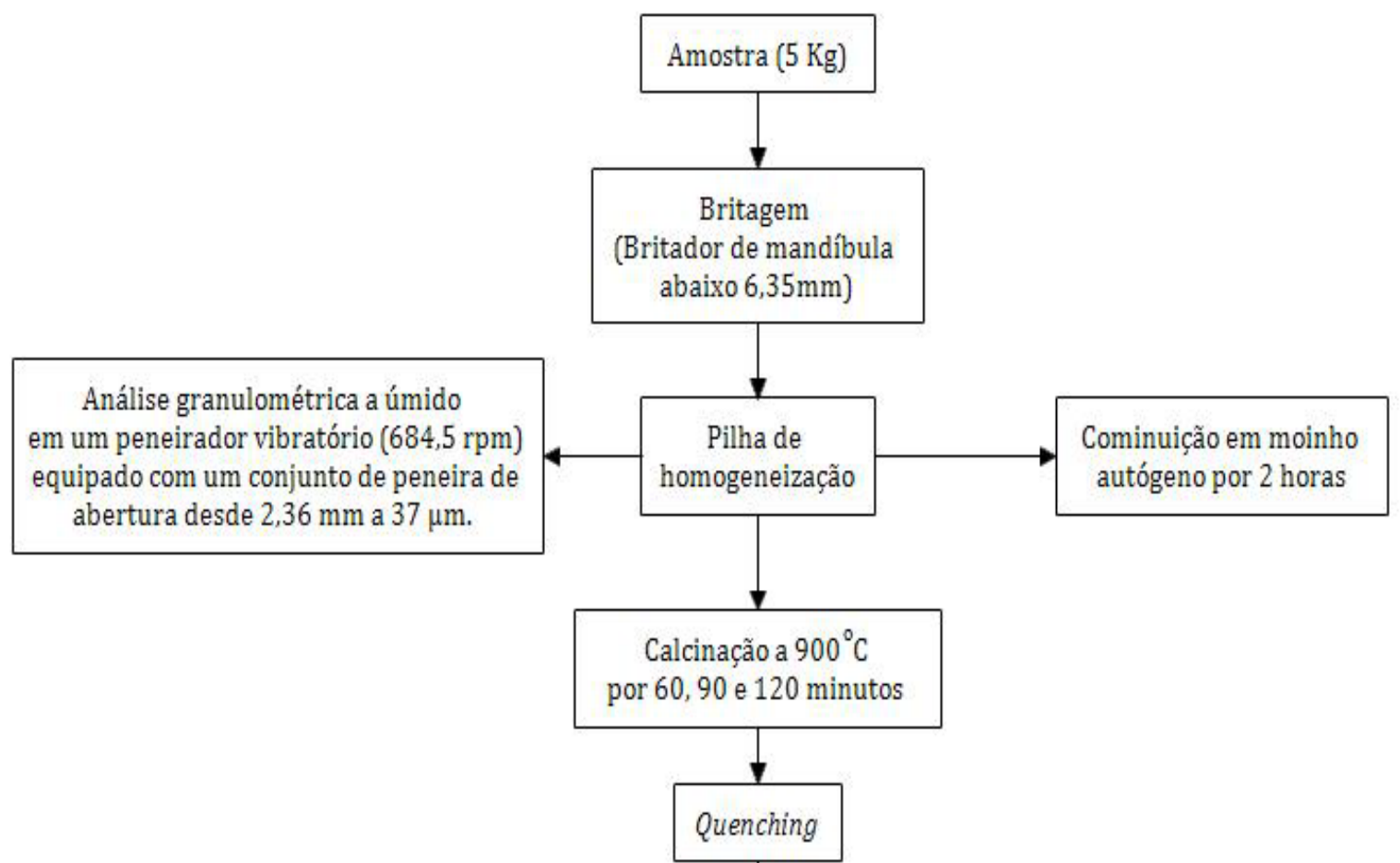

Figura 2 - Fluxograma de trabalho 


\section{RESULTADOS E DISCUSSÕES}

De acordo com os ensaios de análise granulométrica a úmido, Figura 3, observa-se que, após a britagem, aproximadamente, $45 \%$ da amostra encontra-se abaixo de $2 \mathrm{~mm}$ e $5 \%$ abaixo de $74 \mu \mathrm{m}$. Esta granulometria foi considerada ótima para os ensaios de moagem de quartzo.

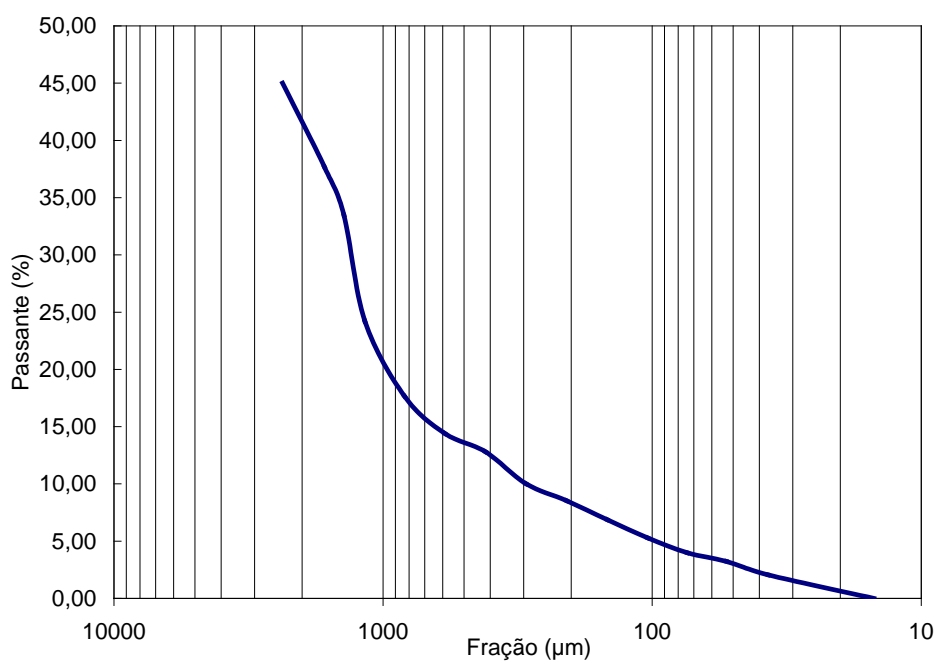

Figura 3 - Representação gráfica dos resultados da análise granulométrica do quartzo após o ensaio de britagem.

O difratograma de raios $X$ da fração obtida acima de $37 \mu \mathrm{m}$, Figura 4, apresenta picos característicos dos minerais microclinio $\left(\mathrm{KAISi}_{3} \mathrm{O}_{8}\right)$, muscovita $((\mathrm{K}, \mathrm{Na})(\mathrm{Al}, \mathrm{Mg}$, $\left.\mathrm{Fe})_{2}\left(\mathrm{Si}_{3.1} \mathrm{Al}_{0.9}\right) \mathrm{O}_{10}(\mathrm{OH})_{2}\right)$ e calcita $\left(\mathrm{CaCO}_{3}\right)$. Já a fração fina, menor que $37 \mu \mathrm{m}$, além desses minerais, contém o mineral albita $\left((\mathrm{Na}, \mathrm{Ca}) \mathrm{Al}(\mathrm{Si}, \mathrm{Al})_{3} \mathrm{O}_{8}\right)$ e observa-se um aumento da intensidade dos picos relativos à muscovita, melhor observado por meio do pico em $10,34^{\circ}$ $(2 \theta)$.

Nesses minerais estão as principais impurezas desta fonte de quartzo, que se destina a produção de silício SiGM. Devido ao efeito negativo na produção de energia elétrica fotovoltaica, provocado por essas impurezas, estas devem ser removidas. De acordo com a Figura 3, observa-se que a fração menor que $37 \mu \mathrm{m}$ corresponde apenas a 2,06\% da massa total. Assim, por apresentar maior quantidade de impurezas, esta fração foi removida antes dos ensaios de purificação. 


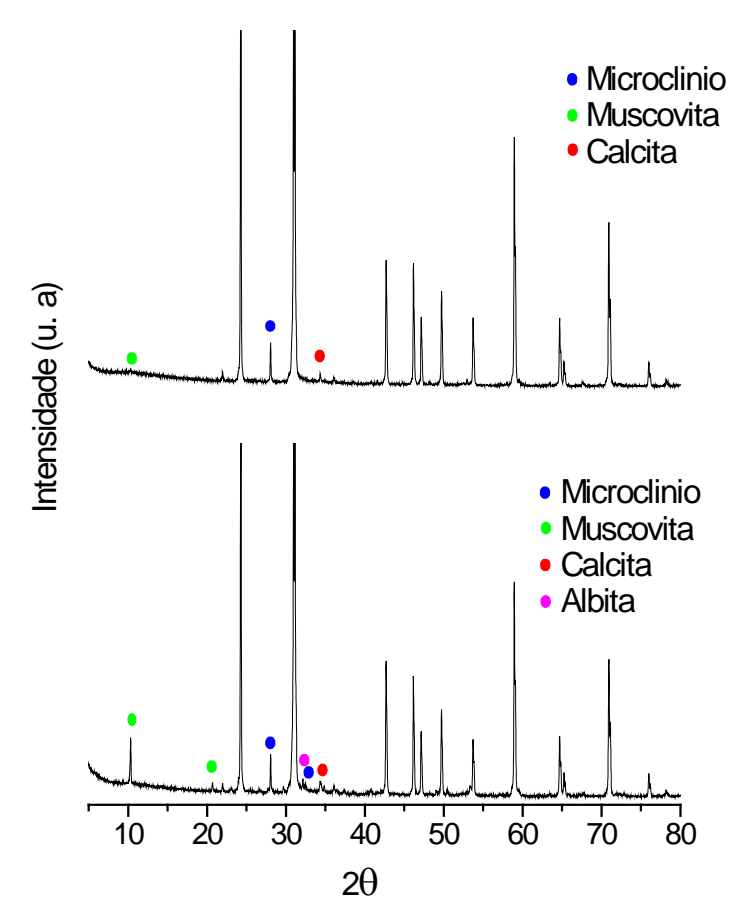

Figura 4 - Difratogramas de raios $X$ das amostras de quartzo, maior e menor que $37 \mu \mathrm{m}$, provenientes do ensaio de análise granulométrica a úmido.

Para detecção de elementos com teores da ordem de algumas ppm (partes por milhão) torna-se necessária a análise por ICP-OES. De acordo com os resultados para a amostra de quartzo moído, Tabela 1, pode-se observar que o teor de $\mathrm{SiO}_{2}$ é de 97,1\%, portanto, abaixo do valor ótimo para a produção de um silício SiGM de qualidade ${ }^{5}$. Os teores dos elementos Boro e Fósforo, estão acima dos valores mínimos exigidos $(0,2 \text { a } 10 \text { ppm })^{7}$, já que no caso deste material os valores encontrados foram 1,4 e $55 \mathrm{ppm}$, respectivamente. Além dessas impurezas, esta amostra também apresenta outros elementos que devem ser removidos. Como em um semicondutor o movimento dos elétrons, no seu interior, se altera quando há impurezas, em sua estrutura, o quartzo utilizado na obtenção do silício SiGM deve conter o mínimo possível de impurezas. Contudo, neste trabalho, buscou-se uma purificação em especial dos elementos dopantes, Boro e Fósforo, presentes no quartzo, uma vez que, são estes os elementos que alteram mais significativamente as características do material. 
Tabela 1: Resultado da análise de ICP-OES para o quartzo após moagem.

\begin{tabular}{|c|c|c|c|}
\hline $\begin{array}{c}\text { Composição } \\
\text { Química }\end{array}$ & Concentração & $\begin{array}{c}\text { Composição } \\
\text { Química }\end{array}$ & Concentração \\
\hline $\mathrm{SiO}_{2}$ & $97,1 \%$ & $\mathrm{Li}$ & $9,4 \mathrm{ppm}$ \\
\hline $\mathrm{Al}$ & $3.300 \mathrm{ppm}$ & $\mathrm{Mg}$ & $119 \mathrm{ppm}$ \\
\hline $\mathrm{B}$ & $<1,4 \mathrm{ppm}$ & $\mathrm{Mn}$ & $47,2 \mathrm{ppm}$ \\
\hline $\mathrm{Ba}$ & $90 \mathrm{ppm}$ & $\mathrm{Na}$ & $3.900 \mathrm{ppm}$ \\
\hline $\mathrm{Ca}$ & $1.300 \mathrm{ppm}$ & $\mathrm{P}$ & $55,0 \mathrm{ppm}$ \\
\hline $\mathrm{Co}$ & $<0,6 \mathrm{ppm}$ & $\mathrm{Sn}$ & $<0,6 \mathrm{ppm}$ \\
\hline $\mathrm{Cr}$ & $10,4 \mathrm{ppm}$ & $\mathrm{Sr}$ & $6,5 \mathrm{ppm}$ \\
\hline $\mathrm{Cu}$ & $3,5 \mathrm{ppm}$ & $\mathrm{V}$ & $<0,6 \mathrm{ppm}$ \\
\hline $\mathrm{Fe}$ & $1.000 \mathrm{ppm}$ & $\mathrm{Zr}$ & $44,9 \mathrm{ppm}$ \\
\hline $\mathrm{K}$ & $605 \mathrm{ppm}$ & & \\
\hline
\end{tabular}

Após a etapa de calcinação, seguida de quenching, as amostras recolhidas foram analisadas por ICP-OES e os resultados obtidos, apresentados na Tabela 2, mostram um significativo aumento nos teores de pureza do $\mathrm{SiO}_{2}$ e uma diminuição dos teores de Boro e de Fósforo, em relação a amostra de quartzo sem tratamento. Como pode ser observado, os teores obtidos se encontram dentro dos valores definidos na literatura como ideais para a obtenção de um silício SiGM ${ }^{5,7}$.

Tabela 2: Comparação dos níveis de $\mathrm{SiO}_{2}$, Boro e Fósforo do quartzo moído e após 60, 90 e 120 minutos de calcinação seguidos de quenching.

\begin{tabular}{|c|c|c|c|c|c|}
\hline \multirow{2}{*}{ Composição } & \multirow{2}{*}{$\begin{array}{c}\text { Limites Aceitáveis } \\
\text { para SiGM }\end{array}$} & \multirow{2}{*}{$\begin{array}{c}\text { Quartzo } \\
\text { Britado }\end{array}$} & & \multicolumn{3}{|c|}{ Calcinação - quenching - moagem } \\
\cline { 4 - 6 } & & & 60 & 90 & 120 \\
\cline { 4 - 6 } & $98-99,5$ & $97,1 \%$ & $99,5 \%$ & $99,4 \%$ & $99,5 \%$ \\
\hline $\mathrm{SiO}_{2}$ & $0,2 \mathrm{ppm}$ & $1,4 \mathrm{ppm}$ & $<0,4 \mathrm{ppm}$ & $<0,4 \mathrm{ppm}$ & $<0,4 \mathrm{ppm}$ \\
\hline $\mathrm{B}$ & $10 \mathrm{ppm}$ & $55 \mathrm{ppm}$ & $<3,0 \mathrm{ppm}$ & $<3,0 \mathrm{ppm}$ & $<3,0 \mathrm{ppm}$ \\
\hline $\mathrm{P}$ & & & & &
\end{tabular}

De acordo com os resultados apresentados na Tabela 2, a partir do tempo de 60 minutos de calcinação se obteve um bom resultado de purificação das amostras de quartzo, e o aumento do tempo de calcinação não provoca mudança significativa nos teores dos elementos analisados.

\section{CONCLUSÃO}


A existência de impurezas torna as etapas de purificação indispensáveis para se atingir o grau de pureza necessário para um quartzo que será utilizado na produção de um SiGM. A etapa de calcinação seguida por quenching resultou em um material com 99,5\% de pureza de $\mathrm{SiO}_{2}$ e um baixo valor nos teores de Boro e de Fósforo, elementos que são utilizados como dopantes no silício solar. Desta maneira, não poderiam estar presentes na matéria-prima que será utilizada para a fabricação do SiGM. Portanto, pode-se concluir que as etapas de beneficiamento realizadas proporcionam uma melhora significativa na qualidade deste quartzo, que visa o seu uso na obtenção de um silício SiGM.

\section{REFERÊNCIAS BIBLIOGRÁFICAS}

1. JACOBSON, M. Z. Review of Solutions to Global Warming, Air Pollution and Energy Security. Energy and Environmental Science. v.2, p. 148-173, 2009.

2. RANJAN, S. et al. Silicon Solar Cell Production. Computers and Chemical Engineering. v.35, p. 1439-1453, 2011.

3. KIM, E.; KWADWO, O. Dissolution Windows for Hydrometallurgical Purification of Metallurgical-Grade Silicon to Solar-Grade Silicon: Eh-pH Diagrams for Fe Silicides. Hydrometallurgy. v.127-128, p. 178-186, 2012.

4. SCHEI, A.; TUSET, J.; TVEIT, H. Production of High Silicon Alloys. Trondheim, Tapir Forlag; 1998.

5. ERGÜL, E. Reduction of Silicon Dioxide by Electrochemical Deoxidation. Dissertação de mestrado- Middle East Technical University, 2010.

6. MACIEL, N. F. et al. Energia Solar para o Meio Rural- Fornecimento de Eletricidade. Viçosa, Ed. CPT, 2008.

7. ENEBAKK et al. Silicon Feedstock for Solar Cells. US 7,381,392 B2. 03 jun. 2008. United States Patent. 